\title{
Nonesterified fatty acids modify inflammatory response and eicosanoid biosynthesis in bovine endothelial cells
}

\author{
G. A. Contreras, W. Raphael, S. A. Mattmiller, J. Gandy, and L. M. Sordillo ${ }^{1}$ \\ Department of Large Animal Clinical Sciences, College of Veterinary Medicine, Michigan State University, East Lansing 48824
}

\begin{abstract}
Intense lipid mobilization during the transition period in dairy cows is associated with increased disease susceptibility. The potential impact of altered plasma nonesterified fatty acids (NEFA) concentrations and composition on host inflammatory responses that may contribute to disease incidence and severity are not known. The objective of this study was to evaluate if increased NEFA concentrations could modify vascular inflammatory responses in vitro by changing the expression of important inflammatory mediators that are important in the pathogenesis of infectious diseases of transition cows such as mastitis and metritis. Bovine aortic endothelial cells (BAEC) were cultured with different concentrations of a NEFA mixture that reflected the plasma NEFA composition during different stages of lactation. The expression of cytokines, adhesion molecules, and eicosanoids were measured to assess changes in BAEC inflammatory phenotype. Addition of NEFA mixtures altered the fatty acid profile of BAEC by increasing the concentration of stearic acid (C18:0) and decreasing the content of arachidonic acid (C20:4n6c) and other long-chain polyunsaturated fatty acids in the phospholipid fraction. A significant increase also occurred in mRNA expression of cytokine and adhesion molecules that are associated with increased inflammatory responses during the transition period. Expression of cyclooxygenase 2, an important enzyme associated with eicosanoid biosynthesis, was increased in a NEFA concentration-dependent manner. The production of linoleic acid-derived eicosanoids 9- and 13-hydroxyoctadecadienoic acids also was increased significantly after treatment with NEFA mixtures. This research described for the first time specific changes in vascular inflammatory response during in vitro exposure to NEFA mixtures that mimic the composition and concentration found in cows during the transition period. These findings could explain, in part, alterations in inflammatory responses observed during intense lipid mobilization
\end{abstract}

Received January 25, 2012.

Accepted May 1, 2012.

${ }^{1}$ Corresponding author: Sordillo@msu.edu stages such as in the transition period of dairy cows. Future studies should analyze specific mechanisms by which high NEFA concentrations induce a vascular proinflammatory phenotype including the effect of 9 and 13-hydroxyoctadecadienoic acids and other lipid mediators.

Key words: nonesterified fatty acid, endothelial cell, transition period, lipid mobilization

\section{INTRODUCTION}

A hallmark of the transition period in dairy cows is intense lipid mobilization. This mechanism of metabolic adaptation is necessary to fulfill the energy deficits experienced by cows in late gestation and early lactation (Drackley, 1999). Lipid mobilization is a dynamic process involving lipolysis and lipogenesis. During the transition period, the rate of lipolysis surpasses that of lipogenesis, inducing the release of NEFA into the bloodstream (Herdt, 2000). As a consequence, increased NEFA concentrations disrupt systemic lipid homeostasis not only quantitatively, but also relative to composition. Previous research demonstrated that enhanced lipolysis during the transition period altered the FA composition of different organs and cell populations, including blood, liver, adipose tissue, and peripheral blood mononuclear cells (Douglas et al., 2007; Contreras et al., 2010). A common change was an increase in the concentrations of SFA, including palmitic (C16:0) and stearic (C18:0) acids. Previous studies in dairy cows associated high plasma NEFA concentrations with impaired host defense mechanisms, with a concomitant increase in disease susceptibility (Lacetera et al., 2004; Scalia et al., 2006; Sordillo et al., 2009). The ways in which increased sera NEFA concentrations may initiate and promote dysfunctional immune and inflammatory responses in transition cows, however, are not fully understood.

Interactions between leukocytes and the vascular endothelium determine efficiency of host inflammatory responses during infectious diseases. Indeed, endothelial cells regulate the trafficking of leukocyte migration to infected tissues (Ley et al., 2007). During the early stages of inflammation, the vasculature expresses sev- 
eral chemotactic proinflammatory cytokines, including IL-6 and IL-8, and different adhesion molecules, including intercellular adhesion molecule (ICAM1) and vascular adhesion molecule (VCAM1), which facilitate circulating leukocyte transmigration into underlying tissues (Sprague and Khalil, 2009). Once the source of inflammation is eliminated, antiinflammatory mediators are produced and adhesion molecule expression is inhibited in vascular endothelium to reduce leukocyte migration and promote tissue remodeling and healing (Frangogiannis, 2008). In humans, the development of certain chronic inflammatory diseases is linked directly to alterations in the resolution mechanisms of inflammation. For example, overexpression of both adhesion molecules (ICAM1 and VCAM1), and certain cytokines (IL-6 and IL-8) is part of the pathophysiology of atherosclerosis and peripheral arterial disease (Weber et al., 1995; Signorelli et al., 2003). Previous studies in dairy cows also showed increase expression of these proinflammatory cytokines and adhesion molecules in tissues during the periparturient period and during the pathogenesis of inflammatory-based diseases such as mastitis (Aitken et al., 2009; Aitken et al., 2011).

Another component of the onset and resolution of inflammation is the biosynthesis of eicosanoids. These lipid molecules are produced by endothelial cells and leukocytes following the oxidation of phospholipidderived PUFA. The main enzymatic pathways for eicosanoid biosynthesis are cyclooxygenases (COX) and lipoxygenases (LOX). Certain COX and LOX metabolites, such as prostaglandins (PG), thromboxanes (TX), and leukotrienes, are potent vasoactive mediators that modulate directly endothelial cell inflammatory responses (Bogatcheva et al., 2005). At the same time, other COX and LOX metabolites, such as lipoxins, resolvins, and certain prostaglandins, have antiinflammatory and proresolving functions that promote the resolution of inflammatory processes (Serhan et al., 2008). Imbalances between the biosynthesis of pro- and antiinflammatory eicosanoids during inflammatory processes are part of the pathogenesis of vascular diseases in humans (Wittwer and Hersberger, 2007).

The distribution of eicosanoids within an inflammatory foci are determined, in part, by the concentration of certain FA that serve as precursors for their biosynthesis (Calder, 2006). The way that shifts in plasma NEFA concentration and composition during the periparturient period may affect the expression of vasoactive eicosanoids, however, is unknown. This information may provide new insights of how increased lipid mobilization is linked with increased disease susceptibility and severity in periparturient cows. The objective of this study was to evaluate how increasing NEFA concentrations could modify vascular inflammatory responses in vitro by changing the expression of cytokines, eicosanoids, and adhesion molecules. The hypothesis of this study was that high NEFA concentrations, such as those seen during the transition period in dairy cows, can increase the proinflammatory phenotype of bovine endothelial cells.

\section{MATERIALS AND METHODS}

\section{Chemicals and Reagents}

Antibiotics and antimycotics, trypsin-EDTA, HEPES buffer, and Ham's F-12K (Kaighn's Nutrient Mixture F-12) were purchased from Cellgro (Herndon, VA). HyClone Laboratories Inc. (Logan, UT) supplied fetal bovine serum (FBS). The RNeasy Mini Kit for isolation of RNA was purchased from Qiagen Inc. (Valencia, CA). Reagents for real-time quantitative PCR (qPCR) were purchased from Applied Biosystems Inc. (Foster City, CA) and Qiagen Inc. All other chemicals were purchased from Sigma (St. Louis, MO).

\section{Vascular Cell Culture}

Bovine aortic endothelial cells (BAEC) were isolated from the aorta of 6 lactating dairy cows by collagenase digestion as described previously (Sordillo et al., 1998). Bovine aortic endothelial cells were cloned to a singlecell level by the limiting dilution method and maintained until confluent as previously described (Sordillo et al., 2008). Ham's F-12K containing 10\% FBS, 2 $\mathrm{m} M$ L-glutamine, $1 \%$ (vol/vol) antibiotic-antimycotic, and $100 \mu \mathrm{g}$ of heparin/mL, but without phenol red, was used as the base culture medium. Bovine aortic endothelial cells were grown in 225 -mm plastic tissueculture flasks until confluence and then passed to tissue culture dishes at a $5.5 \times 10^{6}$ cells $/ \mathrm{mL}$ concentration. Bovine aortic endothelial cells were exposed for 4 or 24 $\mathrm{h}$ to 3 different NEFA mixture concentrations emulating different degrees of lipid mobilization as observed during the transition period: $0.25 \mathrm{~m} M$ for low, $0.5 \mathrm{mM}$ for intermediate, and $0.75 \mathrm{mM}$ for high mobilization intensity. Bovine aortic endothelial cells were exposed to culture media without addition of NEFA mixture $(0$ $\mathrm{m} M)$ as a negative control. Culture media plus albumin at equivalent concentration to the $0.75 \mathrm{~m} M$ NEFA treatment as the NEFA vehicle control and media plus LPS $(50 \mathrm{ng} / \mathrm{mL})$ served as positive inflammation control. Treatments were applied by replacing the base media with the treatments or controls. Three independent rounds of experiments were performed for (1) qPCR, Western blots, and FA analyses; (2) flow cytometry; and (3) eicosanoid detection and quantification. Bovine aortic endothelial cell maximum passage was 9, and 
clones obtained from 3 different cows were used for each experiment.

\section{Cell Viability Assay}

Trypan blue exclusion was used to evaluate cell death. Following treatment of BAEC with the different controls and NEFA mixture concentrations for 4 and $24 \mathrm{~h}$, cells were collected using trypsin, diluted 1:10 in trypan blue, and counted on a hemocytometer. Viable and nonviable cells were counted using a hemocytometer to obtain the percentage of viable cells. Metabolic activity, and thereby cell viability, was measured using the Promega CellTiter-Glo Viability Assay (Promega Corp., Madison, WI), which quantifies the amount of ATP, an indicator of metabolically active cells. Endothelial growth factor $(30 \mu \mathrm{g} / \mathrm{mL})$ was used as a positive control for this assay, as it sustains cell growth. A mixture of substrate and buffer results in cell lysis and generation of a luminescent signal proportional to the amount of ATP present. The amount of ATP directly reflects the number of viable cells. Luminescence was measured using a Wallac Victor3 1420 Multilabel Plate Reader (PerkinElmer Inc., Waltham, MA).

\section{NEFA-Albumin Mixture Solution}

The composition of the NEFA mixture was calculated based upon a previous study that characterized the FA profiles of plasma NEFA in periparturient cows (Contreras et al., 2010). The mixture resembled the FA profile in the NEFA fraction during the first week of lactation when the greatest lipid mobilization intensity was observed and included: myristic (C14:0; 3\%), palmitic (C16:0; 30\%), stearic acid (C18:0; 45\%), oleic $(\mathrm{C} 18: 1 \mathrm{n} 9 c ; 16 \%)$, linoleic $(\mathrm{C} 18: 2 \mathrm{n} 6 c ; 5 \%)$, and docosahexaenoic (C22:6n $3 c ; 1 \%)$ FA. Nonesterified FA were bound to albumin, which is their natural transporter in plasma, to mimic in vivo physiological conditions. The NEFA-albumin mixtures were solubilized by saponification (Kim et al., 2005). Briefly, palmitic (C16:0) and stearic $(\mathrm{C} 18: 0)$ acids were dissolved in ethanol at $90^{\circ} \mathrm{C}$ and further sonicated with a Branson Sonifier 250 (Branson Ultrasonics Corp., Danbury, CT) for $10 \mathrm{~s}$ at an output of $10 \%$. Once readily dissolved, the solution was dried under nitrogen, and then resuspended in 0.1 $M \mathrm{NaOH}$ at $90^{\circ} \mathrm{C}$. Oleic $(\mathrm{C} 18: 1 \mathrm{n} 9 c)$, linoleic $(\mathrm{C} 18: 2 \mathrm{n} 6 c)$, and docosahexaenoic acid $(\mathrm{C} 22: 6 \mathrm{n} 3 c)$ acids were dissolved in $0.1 \mathrm{M} \mathrm{NaOH}$ at $70^{\circ} \mathrm{C}$ and then mixed with the palmitic (C16:0) and stearic (C18:0) acid $\mathrm{NaOH}$ solution. The NEFA mixture solution was complexed with $10 \%$ BSA (FA-free) at $55^{\circ} \mathrm{C}$ for $10 \mathrm{~min}$. The NEFAalbumin mixtures were then filter sterilized $(0.44 \mu \mathrm{m})$ and stored under argon atmosphere at $-20^{\circ} \mathrm{C}$ for future use. The final concentration of the mixture was $100 \mu M$ with a NEFA:albumin molar ratio of $7: 1$.

\section{Lipid Extractions}

Total lipids from media and BAEC were extracted using a hexane:ethanol (1:1) solvent mix as previously described (Contreras et al., 2010). Bovine aortic endothelial cells were harvested by gentle scraping, washed in Hanks' buffered salt solution (HBSS), and centrifuged at $233 \times g$. Prior to lipid extraction, BAEC were resuspended in HBSS to a minimum concentration of $5.5 \times 10^{6}$ cells $/ \mathrm{mL}$. To obtain total lipids, media or BAEC were combined with the solvent mix $(1: 2)$ and vortexed for $10 \mathrm{~min}$, and then centrifuged at 2,095 $\times \mathrm{g}$ for $10 \mathrm{~min}$ at $25^{\circ} \mathrm{C}$. The hexane layer was collected for total FA composition and lipid fractioning. Nonadecanoic acid (C19:0) was used as internal standard.

Lipids were further separated into neutral lipid, NEFA, and phospholipid fractions by solid-phase extraction using aminopropyl (Strata NH2) sorbent cartridges (Phenomenex Inc., Torrance, CA) as described by (Kaluzny et al., 1985). Briefly, after conditioning of the cartridges with hexane, the neutral lipid fraction was eluted with chloroform:2-propanol (2:1), the NEFA with $2 \%$ acetic acid in diethyl ether, and the phospholipid fraction with methanol. 1,2-diheneicosanoylsn-glycero-3-phosphocholine (21:0 phosphatidylcholine) was used as the internal standard for lipid fractioning. Fatty acids from total extractions and each lipid fraction were transesterified and methylated using $20 \%$ methanolic hydrochloric acid for $2 \mathrm{~h}$ at $90^{\circ} \mathrm{C}$ (Browse et al., 1986). Methylated extractions were analyzed using a PerkinElmer Clarus 500 gas chromatography apparatus (PerkinElmer Inc.) with a Supelco SP-2560 column $(100 \mathrm{~m} \times 25 \mathrm{~mm}$ with a $0.2-\mu \mathrm{m}$ film thickness; Supelco Inc., Bellefonte, PA). Analyte elution times were identified using a mix of pure methyl ester standards $(\mathrm{Nu}-$ Chek Prep Inc., Elysian, MN).

\section{Gene Transcript Quantification by qPCR}

Total RNA was extracted from BAEC for quantification of IL-6, IL-8, ICAM1, VCAM1, COX1, COX2, 15LOX1, and $\beta$-actin mRNA transcript expression by qPCR as formerly described (Corl et al., 2008). Briefly, total RNA was extracted using the Qiagen RNeasy Mini Kit (Qiagen Inc.). A DNase digest was performed during the RNA extraction using the RNase-Free DNase Set (Qiagen Inc.). Purified RNA was converted to cDNA using the Applied Biosystems High-Capacity cDNA Archive Kit (Applied Biosystems Inc.). All qPCR assays were conducted using TaqMan gene expression assays from Applied Biosystems Inc. The TaqMan 
primer and probe sets (Table 1) were designed from bovine sequences with the Applied Biosystems Pipeline software and synthesized by Applied Biosystems Inc. Samples were assayed in triplicate with $50 \mathrm{ng}$ of cDNA per reaction along with $10 \mu \mathrm{L}$ of TaqMan Fast Universal PCR Master Mix $(2 \times)$, and $1 \mu \mathrm{L}$ of the appropriate TaqMan Gene Expression Assay Mix $(20 \times)$ on the Applied Biosystems 7500 Fast Real-Time PCR System. A nonreverse transcriptase control was run to ensure that genomic DNA was not being amplified. The relative quantification of each gene was calculated utilizing the 7500 Fast SDS software (version 1.3.1; Gallagher et al., 2003). Data were calculated based on the comparative cycle threshold $(\mathrm{Ct})$ method $\left(2^{-\Delta \Delta \mathrm{Ct}}\right)$ of relative quantification using $\beta$-actin as the control gene (Steibel et al., 2009). The calibrator was the $0 \mathrm{~m} M$ NEFA culture media control cells.

\section{Western Blot Analyses}

Protein quantification was performed by protein blot analysis. Bovine aortic endothelial cells were harvested by gentle scraping. Whole cell lysates were harvested in M-Per reagent (Pierce Biotechnology Inc., Rockford, IL) and centrifuged at $10,000 \times g$ for $10 \mathrm{~min}$ at $4^{\circ} \mathrm{C}$ to remove membrane fractions. Supernatants were collected and total protein was quantified using the Coomassie brilliant blue method. Equal amounts of protein $(30 \mu \mathrm{g})$ were electrophoresed on a $10 \%$
SDS-PAGE gel and transferred to a polyvinylidene difluoride membrane. The Millipore Snap i.d. Protein Detection System (Millipore Corp., Billerica, MA) was used to carry out the remaining steps. The membrane was blocked in $0.5 \%$ dry milk in Tris-buffered saline (TBS) with $0.01 \%$ Tween-20 and washed 3 times with TBS. Membranes were incubated for 10 min with anti-bovine COX1 (1:400 dilution; Abcam PLC, Cambridge, MA), anti-human COX2 (1:200 dilution; Santa Cruz Biotechnology Inc., Santa Cruz, CA), anti-rabbit 15LOX1 (1:2,000; Cayman Chemical Co., Ann Arbor, MI), and anti-human ICAM1 (1:100 dilution; Invitrogen Corp., Carlsbad, CA) in 1\% BSA in TBS and $0.01 \%$ Tween-20. Following 3 washes with TBS, membranes were incubated with the correspondent anti-host IgG secondary antibody labeled with horseradish peroxidase (HRP; 1:3,000 dilution in $0.5 \%$ dry milk; Pierce Biotechnology Inc.) for $10 \mathrm{~min}$ at $25^{\circ} \mathrm{C}$, washed 3 times with TBS, exposed to HRP substrate (Pierce Biotechnology Inc.), and visualized by chemiluminescence using the ChemiDoc XRS (BioRad Laboratories Inc., Hercules, CA) and Quantity One software (Bio-Rad Laboratories Inc.). Anti-human actin (1:3,000 dilution; Millipore Corp.) served as the loading control. Density of the bands was quantified by the Quantity One software. The ratio of specific antibodies:actin was calculated and the values were expressed as a fold change over the $0 \mathrm{~m} M$ NEFA culture media control BAEC.

Table 1. Gene targets and primer sequences for quantitative PCR

\begin{tabular}{|c|c|c|c|}
\hline Target $^{1}$ & Accession no. & Direction & Sequence $\left(5^{\prime}\right.$ to $\left.3^{\prime}\right)$ \\
\hline \multirow[t]{3}{*}{ ICAM1 } & \multirow{3}{*}{ NM-174348 } & Forward & GCAGGTGGTCCACAAACAC \\
\hline & & Reverse & GCAATCCCGCTGGTCTAGTC \\
\hline & & Probe & ATGTCCTGTACGGCCCC \\
\hline \multirow{3}{*}{ VCAM1 } & \multirow[t]{3}{*}{ NM-174484 } & Forward & ACAAAGGCAGAGTACACAAACACTT \\
\hline & & Reverse & GAGGAGGGACTGACCAAGATG \\
\hline & & Probe & CCTGGGAGCAACATTA \\
\hline \multirow[t]{3}{*}{ IL-6 } & \multirow[t]{3}{*}{ X57317 } & Forward & AGGACGGATGCTTCCAATCTG \\
\hline & & Reverse & GAAGACCAGCAGTGGTTCTGAT \\
\hline & & Probe & CAATCAGGCGATTTGC \\
\hline \multirow[t]{3}{*}{ IL-8 } & \multirow[t]{3}{*}{ NM-173925 } & Forward & GCTCTCTTGGCAGCTTTCCT \\
\hline & & Reverse & GGCATCGAAGTTCTGTACTCATTCT \\
\hline & & Probe & CAGAACTGCAGCTTCAC \\
\hline \multirow[t]{3}{*}{ COX1 } & \multirow[t]{3}{*}{ NM-001105323.1 } & Forward & ATGGAGTTCAACCAGCTTTACCA \\
\hline & & Reverse & CAGAAACTGCTCGTAGCTGTAGTC \\
\hline & & Probe & CATGCCCGACTCCTTC \\
\hline \multirow[t]{3}{*}{ COX2 } & \multirow[t]{3}{*}{ NM-174445.2 } & Forward & GGCGATGAGCAGTTGTTCCA \\
\hline & & Reverse & TGCTGTACGTAGTCTTCAATCACAAT \\
\hline & & Probe & CAAGCAGGCTAATCCT \\
\hline \multirow[t]{3}{*}{ 15LOX1 } & \multirow[t]{3}{*}{ NM-174501 } & Forward & GTGCCTTCCGTCTATACATCCTATG \\
\hline & & Reverse & CCCGGATGTTAATTTCCATGGTGTA \\
\hline & & Probe & CCCGGATGTTAATTTCCATGGTGTA \\
\hline \multirow[t]{3}{*}{$\beta$-Actin } & \multirow[t]{3}{*}{ NM-173979 } & Forward & CCGCCCCGCTAGCA \\
\hline & & Reverse & AACTGGTTGCGGTGTCGA \\
\hline & & Probe & CCTTCGCCGCTCCGC \\
\hline
\end{tabular}




\section{Reactive Oxygen Species Determination by Flow Cytometry}

Reactive oxygen species (ROS) generation in BAEC cultures was determined by flow cytometry using the intracellular fluorescent probe carboxy-2'$7^{\prime}$-dichlorofluorescein (DCF) as previously described (Eruslanov and Kusmartsev, 2010). Briefly, after treatments, BAEC were washed with HBSS and collected from culture dishes by trypsinization. Cells were resuspended in $350 \mu \mathrm{L}$ of HBSS before the addition of $100 \mu M$ carboxy-DCF diacetate (Molecular Probes; Invitrogen Corp.). Following 30-min incubation at room temperature, the samples were analyzed with the FACSVantage flow cytometer (Becton Dickinson, Franklin Lakes, NJ). The fluorescence intensity was evaluated for at least 3 independent experiments.

\section{Eicosanoid Detection and Quantification}

Bovine aortic endothelial cells and media were harvested by gentle scraping and addition of ethanol to a $10 \%$ solution by volume. Specimens were then sonicated in a water bath at $4^{\circ} \mathrm{C}$ for $3 \mathrm{~min}$ at output $10 \%$ using a Misonix S-400 sonicator (Qsonica LLC, Newton, CT). Samples were then centrifuged at $4^{\circ} \mathrm{C}$ for 5 min at 3,000 $\times g$ and the supernatant was used for extraction. Lipid mediators were isolated from specimens by solid-phase extraction using Strata X SPE columns (Phenomenex Inc.). Cartridges were first conditioned with $2 \mathrm{~mL}$ of methanol $(\mathbf{M e O H})$ and then washed with $2 \mathrm{~mL}$ of $\mathrm{H}_{2} \mathrm{O}$. Samples were loaded into the cartridge, washed with $2 \mathrm{~mL}$ of $\mathrm{MeOH}(40 \% \mathrm{vol} / \mathrm{vol})$, and finally eluted with $\mathrm{MeOH}$ :acetonitrile (50:50 vol/vol). Eluates were dried using a Savant SpeedVac concentrator (Thermo Electron Corp., West Palm Beach, FL) and then redissolved in acetonitrile:water:formic acid (36:64:0.2 vol/ $\mathrm{vol} / \mathrm{vol})$.

Eicosanoids were isolated using 2 distinct ultra-high pressure liquid chromatography (UPLC) and mass spectrometry (UPLC-MS) methods. Both used reversephase liquid chromatography on a Waters ACQUITY UPLC BEH C18 $1.7-\mu \mathrm{m}$ column $(2.1 \times 100 \mathrm{~mm})$ at a flow rate of $0.6 \mathrm{~mL} / \mathrm{min}$ at $35^{\circ} \mathrm{C}$ and a quadrupole mass spectrometer Waters H-class Acquity UPLC in electrospray negative ionization mode (Waters Corp., Milford, MA). The electrospray voltage was $-3 \mathrm{kV}$ and the turbo ion spray source temperature was $450^{\circ} \mathrm{C}$. Collisional activation used nitrogen as the collision gas. For each method, a $10-\mu \mathrm{L}$ sample was injected 3 consecutive times using a $10-\mu \mathrm{L}$ injection loop. An isocratic mobile phase consisting of acetonitrile:water:formic acid (45:55:0.01; vol/vol/vol) with an analysis time of 15 min was used to measure leukotriene $\mathrm{B}_{4}, \mathrm{PGE}_{2}$, 6-keto $\mathrm{F}_{1 \alpha}\left(\mathrm{PGF}_{1 \alpha}\right), \mathrm{PGF}_{2 \alpha}, 6(\mathrm{R})$-lipoxin $\mathrm{A}_{4}\left(\mathrm{LXA}_{4}\right)$, $\mathrm{TXB}_{2}$, resolvin $\mathrm{D}_{1}\left(\mathrm{RD}_{1}\right)$, and $\mathrm{D}_{2}\left(\mathrm{RD}_{2}\right)$. The second method used an isocratic mobile phase of acetonitrile:m ethanol:water:formic acid (47.4:15.8:26.8:0.01; vol/vol/ $\mathrm{vol} / \mathrm{vol}$ ) and an analysis time of $10 \mathrm{~min}$ to analyze $9(\mathrm{~S})-$ hydroxyoctadecadienoic acid (HODE), 13(S)-HODE, 5(S)-hydroxyeicosatetraenoic acid (HETE), 12(S)HETE, and 15(S)-HETE. Eicosanoids were identified in samples by matching their mass -1 and LC retention time with those of a pure standard. Internal deuterated standards were added before harvesting cells and supernatants to control for sample extraction, injection, and ionization variability. Standards included $\mathrm{PG} \mathrm{D}_{2}-\mathrm{d}_{4}$ $(50 \mathrm{ng} / \mu \mathrm{L}), \mathrm{E}_{2}-\mathrm{d}_{4}(50 \mathrm{ng} / \mu \mathrm{L}), \mathrm{F}_{2 \alpha}-\mathrm{d}_{4}(50 \mathrm{ng} / \mu \mathrm{L}), 5(\mathrm{~S})-$ HETE-d $\mathrm{d}_{8}(50 \mathrm{ng} / \mu \mathrm{L}), 13(\mathrm{~S})-\mathrm{HODE}_{4}(50 \mathrm{ng} / \mu \mathrm{L})$, $9(\mathrm{~S})-\mathrm{HODE}_{-} \mathrm{d}_{4}(50 \mathrm{ng} / \mu \mathrm{L})$, leukotriene D4- $\mathrm{d}_{5}(50 \mathrm{ng} /$ $\mu \mathrm{L}), 15(\mathrm{~S})-\mathrm{HETE}_{-} \mathrm{d}_{8}(50 \mathrm{ng} / \mu \mathrm{L}), 12(\mathrm{~S})-\mathrm{HETE}_{8} \mathrm{~d}_{8}(50$ $\mathrm{ng} / \mu \mathrm{L})$, leukotriene $\mathrm{B}_{4}-\mathrm{d}_{4}(50 \mathrm{ng} / \mu \mathrm{L})$, thromboxane $\mathrm{B} 2-\mathrm{d}_{4}(50 \mathrm{ng} / \mu \mathrm{L}), 6$-keto PGF1 $\alpha-\mathrm{d}_{4}(50 \mathrm{ng} / \mu \mathrm{L})$, and $5(\mathrm{~S}), 6(\mathrm{R})$-lipoxin A4- $\mathrm{d}_{5}(50 \mathrm{ng} / \mu \mathrm{L})$. Extraction and ionization efficiencies were measured for the internal standards by comparing the intensity of the samples with the ion intensity of the extraction controls.

Quantitation of eicosanoid production was performed with Waters Empower 2 software (Waters Corp.). A linear calibration curve with 5 points $\left(\mathrm{R}^{2}>0.99\right)$ was generated for each eicosanoid with standards and internal standards purchased from Cayman Chemical Co. The curves range from 0.013 to $22.68 \mathrm{ng} / \mu \mathrm{L}$. Empower 2 identified the sample peak by matching its retention time with the standard. A response is calculated for each matched peak by dividing the sample peak's response by its internal standard's response. This response was multiplied by the concentration of the internal standard for each analyte. The concentration of each analyte was calculated using the response peak, injection volume, and protein concentration of the sample, and concentrations are reported as picograms of eicosanoid per microgram of protein.

\section{Statistical Analyses}

Statistical evaluation was conducted using the MIXED procedure (SAS v9.1; SAS Institute Inc., Cary, NC). Comparisons of the means were made by ANOVA followed by the Tukey-Kramer honestly significant difference (HSD) post hoc test as necessary. Specific contrasts were performed to evaluate (1) linear and quadratic relationships of the NEFA mixture concentration effect and (2) the presence of albumin as FA transporter in comparison to $0 \mathrm{~m} M$ control and the highest NEFA concentration $(0.75 \mathrm{mM})$. Data are shown as means \pm standard errors of the means. Differences at $P<0.05$ were considered statistically significant. 
Table 2. Fatty acid composition of the bovine aortic endothelial cell phospholipid fraction after $24 \mathrm{~h}$ of culture with different concentrations of a NEFA mixture or albumin as a loading control ${ }^{1}$

\begin{tabular}{|c|c|c|c|c|c|c|c|}
\hline $\mathrm{FA},{ }^{2} \mathrm{~g} / 100 \mathrm{~g}$ & \multicolumn{5}{|c|}{ FFA complex supplementation } & $P$-value & $\begin{array}{c}\text { Aorta lipic } \\
\text { content }\end{array}$ \\
\hline C15:0 & $2.239 \pm 0.7$ & $1.57 \pm 0.5$ & $3.263 \pm 0.92$ & $3.52 \pm 0.96$ & $2.315 \pm 0.3$ & 0.26 & 0.67 \\
\hline C16:0 & $26.27 \pm 1.9$ & $28.4 \pm 1.7$ & $22.93 \pm 1.98$ & $21.96 \pm 2.44$ & $25.36 \pm 1.6$ & 0.07 & 21.36 \\
\hline $\mathrm{C} 16: 1 \mathrm{n} 7 \mathrm{c}$ & $0.957 \pm 0.1$ & $0.89 \pm 0.1$ & $0.813 \pm 0.07$ & $0.631 \pm 0.18$ & $0.988 \pm 0.2$ & 0.10 & 0.44 \\
\hline C18:0 & $27.98 \pm 2.2^{\mathrm{a}}$ & $30.2 \pm 2.6^{\mathrm{a}}$ & $32.98 \pm 2.41^{\mathrm{ab}}$ & $34.99 \pm 2.58^{\mathrm{b}}$ & $34.99 \pm 1.8^{\mathrm{b}}$ & 0.01 & 32.71 \\
\hline $\mathrm{C} 18: \ln 9 t$ & $1.674 \pm 0.3$ & $1.92 \pm 0.4$ & $1.649 \pm 0.58$ & $1.211 \pm 0.3$ & $1.29 \pm 0.2$ & 0.23 & 1.99 \\
\hline $\mathrm{C} 18: 2 \mathrm{n} 6 c$ & $0.815 \pm 0.2$ & $0.75 \pm 0.3$ & $1.663 \pm 0.5$ & $1.83 \pm 0.63$ & $1.392 \pm 0.5$ & 0.13 & 3.04 \\
\hline $\mathrm{C} 18: 3 \mathrm{n} 6 c$ & $0.535 \pm 0.1$ & $0.57 \pm 0.1$ & $0.615 \pm 0.05$ & $0.789 \pm 0.15$ & $0.523 \pm 0.1$ & 0.15 & 0.52 \\
\hline $\mathrm{C} 20: 4 \mathrm{n} 6 c$ & $3.433 \pm 0.8^{\mathrm{c}}$ & $2.49 \pm 0.8^{\mathrm{bc}}$ & $1.871 \pm 0.44^{\mathrm{ab}}$ & $1.648 \pm 0.37^{\mathrm{ab}}$ & $1.34 \pm 0.3^{\mathrm{a}}$ & $<0.01$ & 5.53 \\
\hline $\mathrm{C} 22: 6 \mathrm{n} 3 c$ & $4.547 \pm 1.3$ & $5.04 \pm 2.3$ & $2.182 \pm 1.04$ & $2.893 \pm 1.22$ & $3.488 \pm 1.1$ & 0.14 & 2.74 \\
\hline
\end{tabular}

${ }^{\mathrm{a}-\mathrm{c}}$ Means within a column with different superscript letters differ $(P<0.05)$.

${ }^{1}$ Values are expressed as means \pm SEM $(n=6)$. The FA composition of phospholipids in aorta intima from an early-lactation cow $(n=1)$ is described in the far-right column.

${ }^{2} c=$ cis; $t=$ trans.

\section{RESULTS}

\section{Cell Viability}

No significant changes in viability were observed by trypan blue exclusion at 4 and $24 \mathrm{~h}$ of incubation when BAEC were exposed to $0 \mathrm{mM}$ (no NEFA addition), albumin, or $0.25,0.5$, or $0.75 \mathrm{~m} M$ of the NEFA mixture, with cell death counts below $10 \%$. Similarly, no differences in ATP production, an indirect measure of cell viability, were detected among treatments after 4 and $24 \mathrm{~h}$ of culture (data not shown).

\section{NEFA Supplementation Altered BAEC Phospholipid FA Profiles}

Addition of NEFA mixtures to culture media did not significantly alter the FA composition of the phospholipid membrane of BAEC at $4 \mathrm{~h}$ (results not shown). After $24 \mathrm{~h}$ in culture with the NEFA mixture, however, significant compositional changes were observed (Table 2 ). A significant increase in the concentrations of stearic acid (C18:0) occurred when cells were supplemented with the 0.5 and $0.75 \mathrm{mM}$ NEFA mixtures when compared with $0 \mathrm{~m} M$ or albumin control treatments. A linear and a quadratic effect $(P<0.01)$ on the phospholipid content of stearic acid (C18:0) by NEFA mixture supplementation was demonstrated by contrasts. In addition, a significant decrease was observed in the concentration of cis-vaccenic acid $(\mathrm{C} 18: \ln 7 c)$ with $0.25,0.5$, and $0.75 \mathrm{~m} M$ NEFA mixtures when compared with albumin and $0 \mathrm{~m} M$ treatments and this effect was linear and quadratic $(P<0.01)$. Similarly, arachidonic acid (C20:4n6c) content decreased significantly with $0.25,0.5$, and $0.75 \mathrm{~m} M$ NEFA mixtures when compared with the $0 \mathrm{~m} M$ treatment. Contrast analysis demonstrated a linear and quadratic effect on arachidonic acid $(\mathrm{C} 20: 4 \mathrm{n} 6 c)$ content $(P<0.01)$ in response to NEFA supplementation.

\section{NEFA Supplementation Altered Expression of Cytokine and Adhesion Molecules}

After $24 \mathrm{~h}$ of culture, the gene expression of IL-6 and IL-8 increased linearly in response to the addition of NEFA mixtures at different concentrations (Table 3). Interleukin-6 and IL-8 expressions were significantly lower in BAEC exposed to albumin compared with the $0.75 \mathrm{~m} M$ NEFA group (Table 3). Also, a linear effect was observed in the gene expression of adhesion molecules ICAM1 and VCAM1 in response to NEFA supplementation (Table 3). This effect was reflected in the protein expression of ICAM1 that was enhanced in BAEC exposed to 0.5 and $0.75 \mathrm{~m} M$ NEFA compared with $0 \mathrm{~m} M$ treatment (Figure 1). Lipopolysaccharide exposure was used as a positive inflammatory control and, as expected, induced a strong endothelial cell response by upregulating the gene expression of proinflammatory cytokines (IL-6 and IL-8) and adhesion molecules (ICAM1 and VCAM1). At the protein level, LPS stimulation induced a significant increase in ICAM1 expression (Figure 1).

\section{NEFA Supplementation Increased ROS Concentration in Cultured BAEC}

The BAEC content of ROS was measured by quantifying the cellular concentration of DCF using flow cytometry. This highly fluorescent compound is produced 
Table 3. Effect of NEFA mixture supplementation on gene expression of proinflammatory cytokines and eicosanoid enzymes, generation of reactive oxygen species (ROS), and production of eicosanoids

\begin{tabular}{|c|c|c|c|c|c|c|c|c|c|c|c|}
\hline \multirow[b]{2}{*}{ Item } & \multicolumn{6}{|c|}{ NEFA mixture supplementation ${ }^{1}$} & \multirow[b]{2}{*}{ SEM } & \multicolumn{4}{|c|}{ Contrast } \\
\hline & $0 \mathrm{~m} M$ & $0.25 \mathrm{~m} M$ & $0.5 \mathrm{~m} M$ & $0.75 \mathrm{~m} M$ & Albumin & LPS & & $\begin{array}{c}0.75 \mathrm{~m} M \\
\text { vs. albumin }\end{array}$ & $\begin{array}{l}0 \mathrm{~m} M \text { vs. } \\
\text { albumin }\end{array}$ & Linear & Quadratic \\
\hline \multicolumn{12}{|l|}{ Gene $^{2}$} \\
\hline$I L-6$ & 20.131 & 19.019 & 17.694 & 15.939 & 19.169 & 9.378 & 1.023 & 0.007 & NS & $<0.001$ & $\mathrm{NS}^{5}$ \\
\hline$I L-8$ & 9.961 & 8.875 & 7.617 & 7.010 & 9.069 & 4.464 & 0.643 & 0.009 & NS & $<0.001$ & NS \\
\hline VCAM1 & 13.440 & 12.057 & 9.836 & 9.638 & 12.028 & 6.444 & 0.739 & 0.003 & NS & $<0.001$ & NS \\
\hline ICAM1 & 9.532 & 9.119 & 8.034 & 7.125 & 9.088 & 3.643 & 0.598 & $<0.001$ & NS & $<0.001$ & NS \\
\hline COX2 & 17.009 & 16.039 & 15.260 & 12.786 & 17.254 & 7.185 & 1.147 & 0.011 & NS & 0.003 & NS \\
\hline $15 \mathrm{LOX} 1$ & 21.686 & 21.559 & 21.194 & 20.817 & 21.280 & 19.969 & 0.766 & NS & NS & 0.027 & NS \\
\hline $\operatorname{ROS}^{3}$ & 164.210 & 184.190 & 265.690 & 292.280 & 182.160 & 262.470 & 26.256 & 0.007 & NS & $<0.001$ & NS \\
\hline \multicolumn{12}{|l|}{ Eicosanoid $^{4}$} \\
\hline $\mathrm{PGE}_{2}$ & 0.010 & 0.016 & 0.009 & 0.009 & 0.012 & 0.061 & 0.012 & NS & NS & NS & NS \\
\hline $\mathrm{PGF}_{1}$ & 0.071 & 0.068 & 0.074 & 0.048 & 0.012 & 1.809 & 0.420 & 0.045 & 0.002 & NS & NS \\
\hline $\mathrm{PGF}_{2}$ & 0.016 & 0.009 & 0.010 & 0.008 & 0.007 & 0.029 & 0.004 & NS & 0.001 & 0.014 & NS \\
\hline $\mathrm{TXB}_{2}$ & 0.453 & 0.359 & 0.221 & 0.221 & 0.215 & 0.543 & 0.052 & NS & $<0.001$ & $<0.001$ & NS \\
\hline 9-HODE & 0.047 & 1.372 & 2.299 & 3.248 & 0.032 & 0.051 & 0.265 & $<0.001$ & NS & $<0.001$ & NS \\
\hline 13-HODE & 0.061 & 2.088 & 3.306 & 3.982 & 0.044 & 0.067 & 0.276 & $<0.001$ & NS & $<0.001$ & $<0.0001$ \\
\hline 12-HETE & 0.900 & 0.689 & 0.579 & 0.266 & 0.390 & 0.867 & 0.219 & NS & NS & NS & NS \\
\hline 15-HETE & 0.380 & 0.376 & 0.322 & 0.107 & 0.148 & 0.559 & 0.252 & NS & NS & NS & NS \\
\hline
\end{tabular}

Bovine aortic endothelial cells (BAEC) were supplemented with a NEFA mixture or vehicle control (albumin) at different concentrations for 24 h. As a positive proinflammator control, BAEC were stimulated with LPS for $12 \mathrm{~h}$. Values are LSM for different treatments and controls.

${ }^{2}$ Values for gene expression are shown as $\Delta$ cycle threshold $(\Delta \mathrm{Ct})$. ICAM1 = Interleukin, intercellular adhesion molecule 1 ; VCAM1 $=$ vascular adhesion molecule $1 ;$ COX $=$ cyclooxygenase; LOX = lipoxygenase.

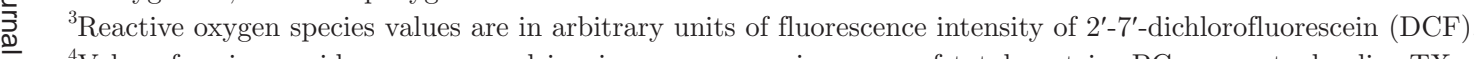

을 $\quad{ }^{4}$ Values for eicosanoids are expressed in picograms per microgram of total protein. PG $=$ prostaglandin, TX $=$ thromboxane; HODE $=$ hydroxyoctadecadienoic acid; HETE $=$

$\rightarrow$ hydroxyeicosatetraenoic acid. 


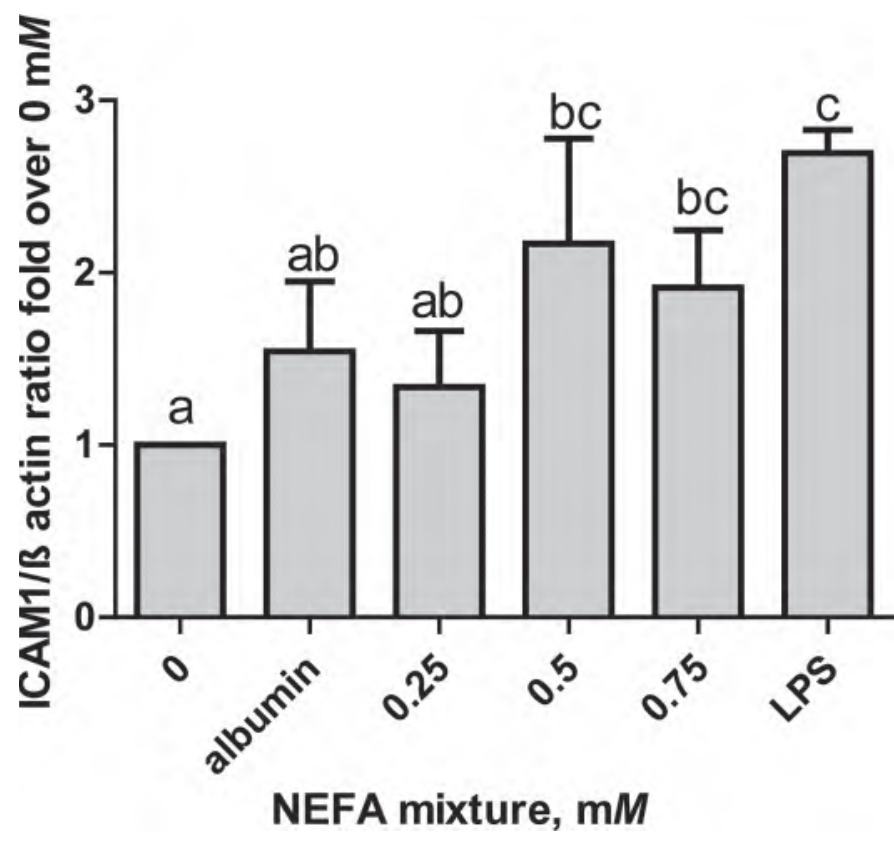

Figure 1. Bovine aortic endothelial cells (BAEC) were supplemented with an albumin (vehicle control) or NEFA mixture at 3 concentrations for $24 \mathrm{~h}$. As a positive proinflammatory control, BAEC were stimulated with LPS for $12 \mathrm{~h}$. The effect of NEFA treatment on BAEC protein expression of intercellular adhesion molecule 1 (ICAM1) was assessed by protein blot. Values are expressed as means \pm SEM of the ratio of ICAM1 to actin as a fold change over the 0 $\mathrm{m} M$ NEFA-supplemented BAEC. Bars with different letters $(\mathrm{a}-\mathrm{c})$ are significantly different $(P<0.05)$.

by the oxidation of carboxy-DCF diacetate by hydrogen peroxide or superoxide anion. As summarized in Table 3 , DCF concentrations increased linearly in response to NEFA mixture exposure. Albumin-supplemented cells had lower ROS content than BAEC exposed to 0.75 $\mathrm{m} M$ NEFA (Table 3). Stimulation with the positive inflammatory control (LPS) also enhanced the concentration of DCF in BAEC.

\section{NEFA Supplementation Altered Lipid Mediator Biosynthesis in BAEC}

Eicosanoid Enzymes. Changes in NEFA mixture concentrations in cultured media did not induce significant changes in the gene expression of COX1 (data not shown). Changes also were not detected when BAEC were supplemented with albumin or stimulated with LPS (positive inflammatory control). Similarly, no changes occurred in the protein expression of COX1 of BAEC cells when cultured for $24 \mathrm{~h}$ with different NEFA mixture concentrations or both controls albumin and LPS (Figure 2a). In contrast to COX1, COX2 mRNA expression increased linearly in a NEFA mixture concentration-dependent manner (Table 3). At the same time, BAEC exposed to albumin had significantly lower COX2 transcription compared with $0.75 \mathrm{mM}$ NEFA-supplemented cells (Table 3). The expression of COX2 protein was significantly augmented when BAEC where exposed to $0.75 \mathrm{~m} M$ NEFA (Figure 2b). The gene expression of 15LOX1 was increased linearly in response to NEFA supplementation (Table 3).

Lipid Mediator Biosynthesis. The concentrations of COX- and 15LOX-derived metabolites were determined by UPLC-MS. At $24 \mathrm{~h}$ of supplementation, $\mathrm{PGE}_{2}$ concentration did not differ among treatments or control groups (Table 3). Concentrations of $\mathrm{PGF}_{1}$ were significantly higher in LPS-stimulated cells compared with other treatment groups $(P<0.05)$. Albumin controls had a significantly lower $\mathrm{PGF}_{1}$ production compared with 0 and $0.75 \mathrm{~m} M$ NEFA groups (Table 3 ). Similar to $\mathrm{PGF}_{1}, \mathrm{PGF}_{2}$ and thromboxane $\mathrm{B} 2$ biosynthesis was higher in the LPS group compared with those supplemented with albumin or any NEFA concentration $(P<0.05)$. Supplementation of albumin reduced the biosynthesis of both arachidonic acid (C20:4n6c) metabolites compared with $0 \mathrm{~m} M$ treatment (Table 3 ). Interestingly, a linear reduction in the production of $\mathrm{PGF}_{2}$ and $\mathrm{TXB}_{2}$ occurred in response to NEFA supplementation (Table 3 ).

Changes were observed in the BAEC production of linoleic acid (C18:2n6c)-derived eicosanoids after exposure to the treatments. Both 9-HODE and 13-HODE concentrations increased linearly after NEFA mixture supplementation (Table 3). Furthermore, a quadratic effect was also found on the production of 13-HODE in response to the addition of NEFA mixtures at different concentrations (Table 3). No changes in the production of these metabolites were observed when BAEC were exposed to the positive inflammatory control (LPS) compared with both $0 \mathrm{~m} M$ and albumin treatment groups. As for 15LOX-derived arachidonic acid (C20:4n6c) metabolites, including 12 and 15 HETE, no significant changes in their biosynthesis occurred as a result of exposure to different concentrations of NEFA mixtures (Table 3 ).

\section{DISCUSSION}

Intense lipid mobilization during the transition period of dairy cows releases abundant NEFA from adipose tissue, inducing alterations in plasma NEFA composition and concentrations (Contreras et al., 2010). Previous work reported changes in leukocyte function with exposure to high NEFA concentration (Lacetera et al., 2004; Scalia et al., 2006). However, to our knowledge, this is the first study to report changes in endothelial inflammatory responses after supplementation with a NEFA mixture that mimic transition cow plasma NEFA concentration and composition. These 


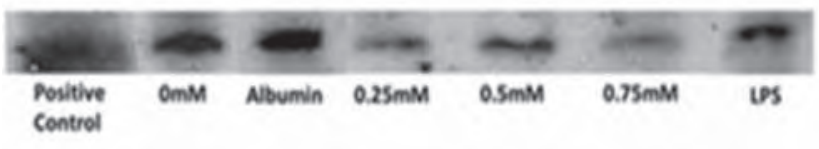

(a)

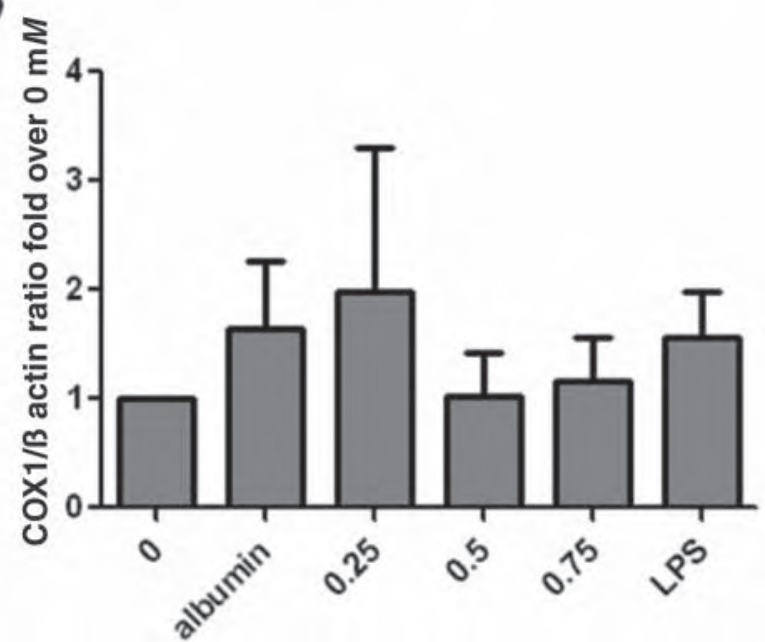

NEFA mixture, $\mathrm{m} M$

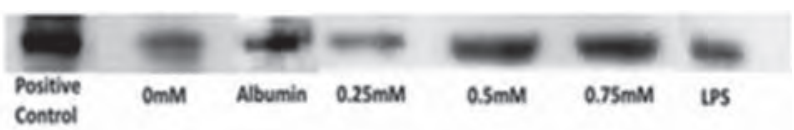

(b)

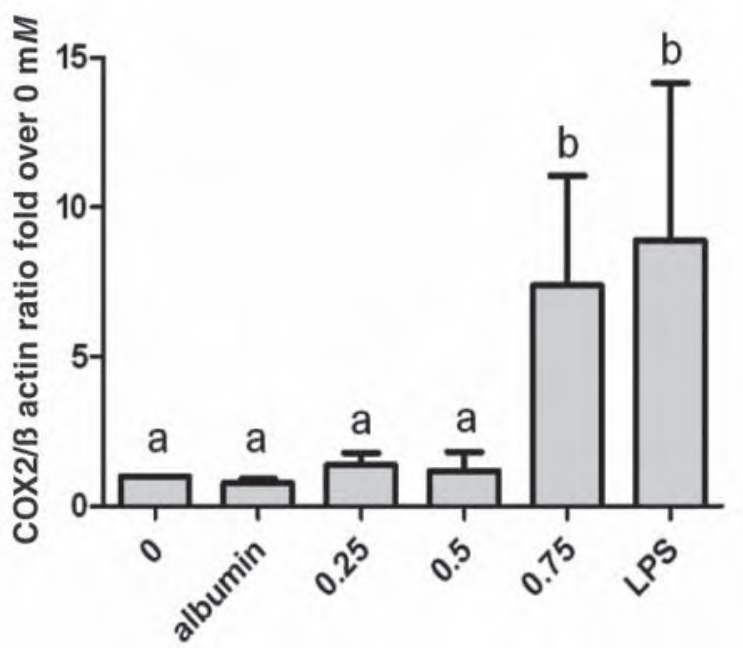

NEFA mixture, $\mathrm{m} M$

Figure 2. Bovine aortic endothelial cell (BAEC) cyclooxygenase (COX) protein expression in response to supplementation with an albumin or NEFA mixture at different concentrations for $24 \mathrm{~h}$ or stimulation with LPS for $12 \mathrm{~h}$. Values are expressed as means \pm SEM of the ratio of (a) COX1 or (b) COX2 to actin as a fold change over the $0 \mathrm{~m} M$ NEFA-supplemented BAEC. Bars with different letters (a and b) are significantly different $(P<0.05)$. Protein bands in the picture were derived from different experiments and subsequently compiled for the figure.

changes included alterations in BAEC phospholipid FA composition, increased gene and protein expression of adhesion molecules and proinflammatory cytokines, enhanced generation of ROS, and alterations in the biosynthesis of eicosanoids from the COX2 and 15LOX enzymatic pathways.

Significant changes in BAEC phospholipid FA content were observed only after exposing BAEC for $24 \mathrm{~h}$ to different NEFA mixture concentrations. This is in agreement with other studies where the phospholipid content of endothelial cells changed significantly only after at least $24 \mathrm{~h}$ of culture (Ferguson et al., 1975; Couloubaly et al., 2007). Héliès-Toussaint et al. (2006) reported that supplementation with SFA increased their concentrations in endothelial phospholipids and, at the same time, this addition was balanced by a decrease in the concentrations of PUFA of both n- 3 and n- 6 series. Similarly, our study showed a significant increase in the concentration of stearic acid (C18:0) and a significant reduction in PUFA, such as vaccenic $(\mathrm{C} 18: 1 \mathrm{n} 7 c)$ and arachidonic $(\mathrm{C} 20: 4 \mathrm{n} 6 c)$ acids. Endothelial cells have a reduced ability to store FA as triglycerides and it was expected that the majority of FA would either be directed to phospholipid biosynthesis or become $\beta$-oxidized in the mitochondria (Héliès-Toussaint et al., 2006). Interestingly, of the supplied SFA [palmitic
(C16:0) and stearic (C18:0)], only stearic (C18:0) increased significantly in the phospholipid content. These changes could be related to the higher concentration of stearate (C18:0, 45\%) in comparison to palmitate (C16:0, 30\%). Moreover, palmitic acid (C16:0) is more efficient in generating acyl-CoA molecules for mitochondrial $\beta$-oxidation than stearic acid (C18:0) due to its shorter chain length (Crunkhorn et al., 2007). Therefore, it may be expected that palmitic acid (C16:0) would be used mainly as energy substrate over stearic acid (C18:0). Results from this study only reflect the influence of plasma NEFA to endothelial cell FA composition and do not take into account the contribution of other plasma lipid fractions usually transported by lipoproteins such as cholesterol esters, triglycerides, and phospholipids. The contribution of esterified FA on phospholipid composition is tissue specific and is largely determined by the activity of lipoprotein lipases, produced by parenchymal cells, monocytes, adipocyte, and myocytes (Engler et al., 1999; Davies et al., 2010). The experiments in this study, however, demonstrated the possibility of manipulating the FA content of endothelial cells by supplementing NEFA mixtures to reflect specific vascular FA profiles found in vivo.

After $24 \mathrm{~h}$ of supplementation with NEFA mixtures, the phospholipid FA content of BAEC in our study 
partially resembled the phospholipid content of aorta intima phospholipids in vivo (Table 2). Concentrations of oleic and arachidonic acids were lower in cultured BAEC when compared with the content in the aorta. This may be reflecting the low concentrations of oleic $(17.2 \%)$ and arachidonic $(0.4 \%)$ acid in the FBS used in the present study for media preparation. Previously, Stoll and Spector (1984) reported that the FA content of serum greatly influenced the FA profile of phospholipids in primary cells or cell lines. Future studies with cultured bovine cells should closely evaluate the FA content of the media supplemented, as this fact could influence the phospholipid composition of cells. In addition, currently, no published studies are available that cite the dynamics of FA composition of vascular endothelial cells during the periparturient period. Based on our results, it is likely that higher concentrations of SFA and reduced content of PUFA, such as those observed in the plasma of transition cows, induce changes in the phospholipid content of endothelium. In humans, high concentrations of palmitate and stearate have detrimental effects on endothelial function, including a decrease in cellular membrane fluidity and induction in the expression of vascular adhesion molecules (Harvey et al., 2010). In dairy cows, trafficking processes are altered during the transition period as indicated by changes in leukocyte adhesion molecule expression and specific leukocyte cellular distribution (Weber et al., 1995; Shafer-Weaver et al., 1999). Currently, it is unknown if changes in the physical properties of vascular phospholipid bilayers induced by high concentrations of plasma NEFA may affect leukocyte migration patterns.

After exposing BAEC to NEFA concentrations over $0.5 \mathrm{~m} M$ for $24 \mathrm{~h}$, both ICAM1 and VCAM1 increased their gene and protein expression. Previous studies in endothelial cells reported enhanced expression of both adhesion molecules during supplementation of palmitic and stearic acids, the main FA in the NEFA mixture used in this report. Harvey et al. (2010) exposed human aortic endothelial cells to BSA bound myristic, stearic, and palmitic acids for $24 \mathrm{~h}$ reporting enhanced surface expression of ICAM1 as measured by flow cytometry. They demonstrated that during supplementations of stearic acid at 50 to $100 \mu \mathrm{M}$, ICAM1 expression was induced in response to nuclear factor $\kappa \mathrm{B}(\mathbf{N F}-\kappa \mathbf{B})$ activation. Similar to SFA, linoleic acid- (C18:2n6c) derived eicosanoids 9- and 13-HODE also are capable of inducing the expression of ICAM1 and VCAM1 in endothelial cells in a concentration-dependent manner by phosphorylation of inhibitor of I $\kappa \mathrm{B}(\mathrm{I} \kappa \mathrm{B}-\alpha)$ and NFкB (Friedrichs et al., 1999; Viita et al., 1999). Both 9- and 13-HODE were increased significantly in our experiments when BAEC were cultured with $0.5 \mathrm{~m} M$ and $0.75 \mathrm{~m} M$ NEFA mixtures. The enhanced expression of vascular adhesion molecules are implicated in the pathology of several inflammatory-based vascular diseases in humans (Weber et al., 1995; Signorelli et al., 2003). The increased expression of ICAM1 and VCAM1 in response to high concentrations of NEFA may contribute to dysfunctional inflammatory responses in periparturient dairy cattle (Aitken et al., 2011) and merits further investigation.

Interleukin-6 and IL-8 transcription also was upregulated after $24 \mathrm{~h}$ of NEFA exposure. Interleukin6 -enhanced expression was previously linked to NF- $\kappa \mathrm{B}$ activation by palmitic (C16:0), stearic (C18:0), and linoleic $(\mathrm{C} 18: 2 \mathrm{n} 6 c)$ acids, as demonstrated in pulmonary artery and coronary artery endothelial cells (Toborek et al., 1996; Staiger et al., 2006). Furthermore, palmitic acid (C16:0) plasma levels in humans were directly correlated to IL-6 content in blood (Staiger et al., 2006). Similarly, IL-8 transcription enhancement in human aortic cells is also mediated by palmitic (C16:0) and oleic (C18:1n9c) acids (Packard and Libby, 2008). Although an induction mechanism for IL-8 expression was not established in vascular cells, palmitate $(\mathrm{C} 16: 0)$ and stearate (C18:0) metabolism induce IL-8 expression through de novo ceramide synthesis and the activation of p38 and JNK kinases in human macrophages (Håversen et al., 2009). Interleukin-6 and IL- 8 are reported as inflammatory markers in human diseases characterized with high concentrations of plasma NEFA, such as obesity and diabetes (Dandona et al., 2004). Dairy cows also are characterized by high plasma NEFA concentrations during exacerbated lipid mobilization and this is directly associated with the incidence of inflammatory diseases such as clinical mastitis and metritis (Melendez et al., 2009). In the case of clinical mastitis, enhanced expression of IL- 6 and IL- 8 is associated with the pathogenesis of this disease when caused by coliform bacteria (Aitken et al., 2011). Currently, the mechanisms by which IL-6 and IL- 8 expression is induced by high plasma NEFA concentrations and how this affects susceptibility to inflammatory based diseases remains unknown.

Nonesterified FA supplementation at $0.5 \mathrm{~m} M$ and $0.75 \mathrm{~m} M$ concentrations enhanced gene and protein expression of COX2. Although not demonstrated in endothelial cells, previous research in monocytes concluded that SFA, especially laureate and palmitate, enhance the expression of this eicosanoid enzyme through toll-like receptor 4 signaling (Lee et al., 2001). The activation of this receptor is sufficient to induce NF$\kappa \mathrm{B}$ inflammatory pathway and, therefore, enhance the gene and protein expression of COX2. Interestingly, at the time of sample collection ( $24 \mathrm{~h}$ after NEFA supplementation), only LPS-stimulated cells had a significant elevation in the gene expression of 15LOX compared 
with nonsupplemented controls. Possibly, transcriptional activity at this time is diminished due to the observed increased concentrations of linoleic acid products, including 13-HODE, which may act as negative feedback signal for 15LOX expression (Lee et al., 2001). A better characterization of the interactions of SFA, such as palmitic and stearic acids, and the linoleic acid products on COX2 and 15LOX activity in endothelial cells is needed. The effect of transient and continuous elevations in NEFA concentrations during the transition period should also be characterized.

Previously published reports in transition cows documented increased SFA content with a concomitant decrease in PUFA within mononuclear cells obtained during times of intense lipid mobilization (Contreras et al., 2010). A possible consequence of these changes is the alteration of substrate availability for eicosanoid biosynthetic pathways, including COX and 15LOX. Bovine aortic endothelial cell supplementation with higher concentrations of NEFA induced a reduction in the phospholipid content of arachidonic acid (C20:4n6c) and other PUFA of 20 or more carbon structure. Decreased availability of this group of PUFA may have induced the use of alternate substrates such as 18-carbon-chain PUFA. In fact, we obtained a significantly higher production of linoleic acid $(\mathrm{C} 18: 2 \mathrm{n} 6 c)$ metabolites of the 15LOX pathway and 9- and 13-HODE and observed no changes in 5-, 12-, and 15-HETE, which are arachidonic $(\mathrm{C} 20: 4 \mathrm{n} 6 c)$ acid derivatives. These shifts in the 15LOX pathway final products could be explained by either short supply of arachidonic acid in our culture media or the higher affinity of 15-LOX for linoleic acid (C18:2n6c) over arachidonic acid and other FA of 20 carbons (Brash et al., 1997). A possible consequence of higher concentration of linoleic acid (C18:2n6c) metabolites is an alteration of inflammation resolution processes. Although not demonstrated in endothelial cells, 9- and 13-HODE are known to interfere with the antiinflammatory actions of peroxisome proliferator-activated receptors (PPAR). For example, 13-HODE downregulates PPAR $\gamma$ activity (Hsi et al., 2002). Furthermore, high levels of these metabolites are highly correlated with endothelial dysfunction and atherosclerosis in humans (Verma et al., 2003). Thus, elevations in the production of 15LOX linoleic acid (C18:2n6c) derivatives due to increased NEFA concentrations may extend endothelial inflammation processes. Complementary studies should look at the effect of increased plasma NEFA and other factors that determine PUFA availability to eicosanoid enzymes, including phospholipase activity and specific availability of selected FA.

Enhanced concentrations of 9- and 13-HODE may not be completely explained by 15 LOX activity. Nonenzymatic lipid peroxidation is an alternate source of these linoleic acid metabolites. This type of oxidation is initiated by either free radicals such as superoxide anion $\left(\mathrm{O}_{2}^{-}\right)$or by singlet oxygen or ozone (Niki, 2009). Free radical oxidation is exacerbated during oxidative stress states such as those observed in obese individuals and periparturient dairy cows (Furukawa et al., 2004; Sordillo and Aitken, 2009). In the case of linoleic acid, 9- and 13-hydroxyperoxyoctadecadienoic acid (HPODE) are the initial products of nonenzymatic peroxidation that are further oxidized to 9- and 13HODE. Interestingly, supplementation with 0.5 and $0.75 \mathrm{~m} M$ NEFA mixtures increased the concentration of ROS as measured by fluorescence intensity. These results confirm that high NEFA concentrations may induce oxidative stress and could, as a result, promote nonenzymatic oxidation of phospholipids in the cellular membrane. In the future, it will be necessary to determine the nonenzymatic $=$ dependent generation of lipid mediators of inflammation as a consequence of high NEFA concentration exposure by inhibiting specific eicosanoid enzymes, such as COX and LOX.

Supplementation of different concentrations of the proposed NEFA mixtures containing albumin as transporter significantly reduced the biosynthesis of key proinflammatory COX derivatives. Consequently, it is not possible to determine the specific effects of the NEFA from the potential confounding effects of the albumin. Linoleic acid, a component of the supplemented NEFA mixture, may have reduced the activity of COX2-catalyzed PG biosynthesis. Limited PG biosynthesis in the presence of linoleate was demonstrated previously in bovine pulmonary artery endothelial cells and placental structures (Kaduce et al., 1982; Cheng et al., 2011). The presence of albumin in the NEFA mixture also could explain reductions in PG biosynthesis because of its potent activity as a ligand binder that could have reduced the availability of $\mathrm{PGH}_{2}$ for prostaglandin synthases (Roche et al., 2008). Furthermore, albumin is known to reduce the half-life of arachidonic acid- $(\mathrm{C} 20: 4 \mathrm{n} 6 c)$ derived compounds due to the strong alkalinity of the $\mathrm{PG}$ binding site that accelerates the catabolism of those metabolites (Fitzpatrick et al., 1984; Yang et al., 2002). These albumin properties were not taken into account when designing the experiments reported in this work and require further analysis, especially in studies evaluating lipid mediator biosynthesis that deliver FA using albumin as a transporter.

Stages of energy imbalance in mammals are linked directly with inflammatory-based diseases. In humans, several studies established that alterations in lipid homeostasis induced by overnutrition are part of the pathophysiology of atherosclerosis, type-2 diabetes, and metabolic syndrome (Boden, 2008; Scaglione et al., 2010). Similarly, dairy cows face severe energy imbal- 
ances during the transition period, the lactation stage with highest incidence of inflammatory-based diseases such as mastitis, metritis, and laminitis (Sordillo et al., 2009). In the present study, we demonstrated that alterations in NEFA concentration can enhance the proinflammatory phenotype of endothelial cells. Nonesterified FA supplementation altered the BAEC phospholipid FA profile, enhanced expression of adhesion molecules and cytokines, increased the production of ROS, and promoted the biosynthesis of specific linoleic acid derived metabolites with known proinflammatory functions, including 9- and 13-HODE. These factors could modify tissue inflammatory responses and leukocyte migration. Future studies should analyze specific mechanisms by which NEFA induce inflammatory responses. It is necessary to evaluate the activation of proinflammatory intracellular signaling pathways upon NEFA supplementation and their interaction with eicosanoid biosynthetic pathways. This work has identified specific metabolites such as linoleic acid-derived 9- and 13-HODE as possible key players in the development and maintenance of the vascular proinflammatory phenotype.

\section{ACKNOWLEDGMENTS}

The authors acknowledge Thomas Herdt (Department of Large Animal Clinical Sciences, Michigan State University, East Lansing) for his assistance with the FA analyses. The authors also thank Justin Zyskowski (Diagnostic Center for Population and Animal Health, East Lansing, MI) for technical assistance, Chris Corl (Department of Large Animal Clinical Sciences, Michigan State University) for laboratory analyses, and Juan David Munoz (Department of Crop and Soil Sciences, Michigan State University) for advice on the statistical analysis. This project was supported, in part, by Agriculture and Food Research Initiative Competitive Grants Programs 2011-67015-30179 from the US Department of Agriculture National Institute for Food and Agriculture and by an endowment from the Matilda R. Wilson Fund (Detroit, MI).

\section{REFERENCES}

Aitken, S. L., C. M. Corl, and L. M. Sordillo. 2011. Immunopathology of mastitis: Insights into disease recognition and resolution. J. Mammary Gland Biol. Neoplasia 16:291-304.

Aitken, S. L., E. L. Karcher, P. Rezamand, J. C. Gandy, M. J. VandeHaar, A. V. Capuco, and L. M. Sordillo. 2009. Evaluation of antioxidant and proinflammatory gene expression in bovine mammary tissue during the periparturient period. J. Dairy Sci. 92:589-598.

Boden, G. 2008. Obesity and free fatty acids. Endocrinol. Metab. Clin. North Am. 37:635-646.

Bogatcheva, N. V., M. G. Sergeeva, S. M. Dudek, and A. D. Verin. 2005. Arachidonic acid cascade in endothelial pathobiology. Microvasc. Res. 69:107-127.
Brash, A. R., W. E. Boeglin, and M. S. Chang. 1997. Discovery of a second 15S-lipoxygenase in humans. Proc. Natl. Acad. Sci. USA 94:6148-6152.

Browse, J., P. J. McCourt, and C. R. Somerville. 1986. Fatty acid composition of leaf lipids determined after combined digestion and fatty acid methyl ester formation from fresh tissue. Anal. Biochem. 152:141-145.

Calder, P. C. 2006. Polyunsaturated fatty acids and inflammation. Prostaglandins Leukot. Essent. Fatty Acids 75:197-202.

Cheng, Z., M. Elmes, S. Kirkup, D. R. E. Abayasekara, and D. C. Wathes. 2011. Effects of n-6 polyunsaturated fatty acids on prostaglandin production in ovine fetal chorion cells in vitro in late gestation ewes. Placenta 32:752-756.

Contreras, G. A., N. J. O'Boyle, T. H. Herdt, and L. M. Sordillo. 2010. Lipomobilization in periparturient dairy cows influences the composition of plasma nonesterified fatty acids and leukocyte phospholipid fatty acids. J. Dairy Sci. 93:2508-2516.

Corl, C. M., J. C. Gandy, and L. M. Sordillo. 2008. Platelet activating factor production and proinflammatory gene expression in endotoxin-challenged bovine mammary endothelial cells. J. Dairy Sci. 91:3067-3078.

Couloubaly, S., C. Deloménie, D. Rousseau, J. L. Paul, A. Grynberg and M. L. Pourci. 2007. Fatty acid incorporation in endothelial cells and effects on endothelial nitric oxide synthase. Eur. J. Clin. Invest. 37:692-699.

Crunkhorn, S., F. Dearie, C. Mantzoros, H. Gami, W. S. da Silva, D. Espinoza, R. Faucette, K. Barry, A. C. Bianco, and M. E. Patti 2007. Peroxisome proliferator activator receptor $\gamma$ coactivator-1 expression is reduced in obesity: Potential pathogenic role of saturated fatty acids and p38 mitogen-activated protein kinase activation. J. Biol. Chem. 282:15439-15450.

Dandona, P., A. Aljada, and A. Bandyopadhyay. 2004. Inflammation: The link between insulin resistance, obesity and diabetes. Trends Immunol. 25:4-7.

Davies, B. S. J., A. P. Beigneux, R. H. Barnes, Y. Tu, P. Gin, M. M. Weinstein, C. Nobumori, R. Nyrén, I. Goldberg, G. Olivecrona, A. Bensadoun, S. G. Young, and L. G. Fong. 2010. GPIHBP1 is responsible for the entry of lipoprotein lipase into capillaries. Cell Metab. 12:42-52.

Douglas, G. N., J. Rehage, A. D. Beaulieu, A. O. Bahaa, and J. K. Drackley. 2007. Prepartum nutrition alters fatty acid composition in plasma, adipose tissue, and liver lipids of periparturient dairy cows. J. Dairy Sci. 90:2941-2959.

Drackley, J. K. 1999. Biology of dairy cows during the transition period: The final frontier? J. Dairy Sci. 82:2259-2273.

Engler, M. M., M. B. Engler, D. L. Kroetz, K. D. B. Boswell, E. Neeley, and S. M. Krassner. 1999. The effects of a diet rich in docosahexaenoic acid on organ and vascular fatty acid composition in spontaneously hypertensive rats. Prostaglandins Leukot. Essent. Fatty Acids 61:289-295.

Eruslanov, E., and S. Kusmartsev. 2010. Identification of ROS using oxidized DCFDA and flow-cytometry. Methods Mol. Biol 594:57-72

Ferguson, K. A., M. Glaser, W. H. Bayer, and P. R. Vagelos. 1975. Alteration of fatty acid composition of LM cells by lipid supplementation and temperature. Biochemistry 14:146-151.

Fitzpatrick, F. A., W. F. Liggett, and M. A. Wynalda. 1984. Albumineicosanoid interactions. A model system to determine their attributes and inhibition. J. Biol. Chem. 259:2722-2727.

Frangogiannis, N. G. 2008. The immune system and cardiac repair Pharmacol. Res. 58:88-111.

Friedrichs, B., M. Toborek, B. Hennig, L. Heinevetter, C. Müller, and R. Brigelius-Flohé. 1999. 13-HPODE and 13-HODE modulate cytokine-induced expression of endothelial cell adhesion molecules differently. Biofactors 9:61-72.

Furukawa, S., T. Fujita, M. Shimabukuro, M. Iwaki, Y. Yamada, Y. Nakajima, O. Nakayama, M. Makishima, M. Matsuda, and I. Shimomura. 2004. Increased oxidative stress in obesity and its impact on metabolic syndrome. J. Clin. Invest. 114:1752-1761.

Gallagher, R. E., B. Y. Yeap, W. Bi, K. J. Livak, N. Beaubier, S. Rao, C. D. Bloomfield, F. R. Appelbaum, M. S. Tallman, J. L. Slack, 
and C. L. Willman. 2003. Quantitative real-time RT-PCR analysis of PML-RAR $\alpha$ mRNA in acute promyelocytic leukemia: Assessment of prognostic significance in adult patients from intergroup protocol 0129. Blood 101:2521-2528.

Harvey, K. A., C. L. Walker, T. M. Pavlina, Z. Xu, G. P. Zaloga, and R. A. Siddiqui. 2010. Long-chain saturated fatty acids induce proinflammatory responses and impact endothelial cell growth. Clin. Nutr. 29:492-500.

Håversen, L., K. N. Danielsson, L. Fogelstrand, and O. Wiklund. 2009 Induction of proinflammatory cytokines by long-chain saturated fatty acids in human macrophages. Atherosclerosis 202:382-393.

Héliès-Toussaint, C., S. Gambert, P. Roller, S. Tricot, B. Lacour, and A. Grynberg. 2006. Lipid metabolism in human endothelial cells. Biochim. Biophys. Acta 1761:765-774.

Herdt, T. H. 2000. Ruminant adaptation to negative energy balance. Influences on the etiology of ketosis and fatty liver. Vet. Clin. North Am. Food Anim. Pract. 16:215-230.

Hsi, L. C., L. C. Wilson, and T. E. Eling. 2002. Opposing effects of 15-lipoxygenase-1 and -2 metabolites on MAPK signaling in prostate. Alteration in peroxisome proliferator-activated receptor $\gamma$. J. Biol. Chem. 277:40549-40556.

Kaduce, T. L., A. A Spector, and R. S. Bar. 1982. Linoleic acid metabolism and prostaglandin production by cultured bovine pulmonary artery endothelial cells. Arteriosclerosis 2:380-389.

Kaluzny, M. A., L. A. Duncan, M. V. Merritt, and D. E. Epps. 1985. Rapid separation of lipid classes in high yield and purity using bonded phase columns. J. Lipid Res. 26:135-140.

Kim, F., K. A. Tysseling, J. Rice, M. Pham, L. Haji, B. M. Gallis, A. S. Baas, P. Paramsothy, C. M. Giachelli, M. A. Corson, and E. W. Raines. 2005. Free fatty acid impairment of nitric oxide production in endothelial cells is mediated by IKK $\beta$. Arterioscler. Thromb. Vasc. Biol. 25:989-994.

Lacetera, N., D. Scalia, O. Franci, U. Bernabucci, B. Ronchi, and A. Nardone. 2004. Short communication: Effects of nonesterified fatty acids on lymphocyte function in dairy heifers. J. Dairy Sci. $87: 1012-1014$

Lee, J. Y., K. H. Sohn, S. H. Rhee, and D. Hwang. 2001. Saturated fatty acids, but not unsaturated fatty acids, induce the expression of cyclooxygenase-2 mediated through toll-like receptor 4. J. Biol. Chem. 276:16683-16689.

Ley, K., C. Laudanna, M. I. Cybulsky, and S. Nourshargh. 2007. Getting to the site of inflammation: The leukocyte adhesion cascade updated. Nat. Rev. Immunol. 7:678-689.

Melendez, P., M. P. Marin, J. Robles, C. Rios, M. Duchens, and L. Archbald. 2009. Relationship between serum nonesterified fatty acids at calving and the incidence of periparturient diseases in Holstein dairy cows. Theriogenology 72:826-833.

Niki, E. 2009. Lipid peroxidation: Physiological levels and dual biological effects. Free Radic. Biol. Med. 47:469-484.

Packard, R. R. S., and P. Libby. 2008. Inflammation in atherosclerosis: From vascular biology to biomarker discovery and risk prediction. Clin. Chem. 54:24-38.

Roche, M., P. Rondeau, N. R. Singh, E. Tarnus, and E. Bourdon. 2008. The antioxidant properties of serum albumin. FEBS Lett. $582: 1783-1787$.

Scaglione, R., T. Di Chiara, T. Cariello, and G. Licata. 2010. Visceral obesity and metabolic syndrome: Two faces of the same medal? Intern. Emerg. Med. 5:111-119.

Scalia, D., N. Lacetera, U. Bernabucci, K. Demeyere, L. Duchateau, and C. Burvenich. 2006. In vitro effects of nonesterified fatty acids on bovine neutrophils oxidative burst and viability. J. Dairy Sci. $89: 147-154$.
Serhan, C. N., N. Chiang, and T. E. Van Dyke. 2008. Resolving inflammation: Dual anti-inflammatory and pro-resolution lipid mediators. Nat. Rev. Immunol. 8:349-361.

Shafer-Weaver, K. A., C. M. Corl, and L. M. Sordillo. 1999. Shifts in bovine $\mathrm{CD}^{+}$subpopulations increase T-helper-2 compared with T-helper-1 effector cells during the postpartum period. J. Dairy Sci. 82:1696-1706.

Signorelli, S. S., M. C. Mazzarino, L. Di Pino, G. Malaponte, C. Porto, G. Pennisi, G. Marchese, M. P. Costa, D. Digrandi, G. Celotta, and V. Virgilio. 2003. High circulating levels of cytokines (IL-6 and $\mathrm{TNF} \alpha$ ), adhesion molecules (VCAM-1 and ICAM-1) and selectins in patients with peripheral arterial disease at rest and after a treadmill test. Vasc. Med. 8:15-19.

Sordillo, L. M., and S. L. Aitken. 2009. Impact of oxidative stress on the health and immune function of dairy cattle. Vet. Immunol. Immunopathol. 128:104-109.

Sordillo, L. M., G. A. Contreras, and S. L. Aitken. 2009. Metabolic factors affecting the inflammatory response of periparturient dairy cows. Anim. Health Res. Rev. 10:53-63.

Sordillo, L. M., H. SooHoo, K. M. Aherne, C. C. Reddy, and J. S. Hogan. 1998. A method to reduce glutathione peroxidase levels in primary endothelial cell cultures. Methods Cell Sci. 19:243-253.

Sordillo, L. M., K. L. Streicher, I. K. Mullarky, J. C. Gandy, W. Trigona, and C. M. Corl. 2008. Selenium inhibits 15-hydroperoxyoctadecadienoic acid-induced intracellular adhesion molecule expression in aortic endothelial cells. Free Radic. Biol. Med. 44:34-43.

Sprague, A. H., and R. A. Khalil. 2009. Inflammatory cytokines in vascular dysfunction and vascular disease. Biochem. Pharmacol. $78: 539-552$.

Staiger, K., H. Staiger, C. Weigert, C. Haas, H.-U. Häring, and M. Kellerer. 2006. Saturated, but not unsaturated, fatty acids induce apoptosis of human coronary artery endothelial cells via nuclear factor- $\kappa$ B activation. Diabetes 55:3121-3126.

Steibel, J. P., R. Poletto, P. M. Coussens, and G. J. M. Rosa. 2009. A powerful and flexible linear mixed model framework for the analysis of relative quantification RT-PCR data. Genomics 94:146-152.

Stoll, L. L., and A. A. Spector. 1984. Changes in serum influence the fatty acid composition of established cell lines. In Vitro 20:732738.

Toborek, M., S. W. Barger, M. P. Mattson, S. Barve, C. J. McClain, and B. Hennig. 1996. Linoleic acid and TNF- $\alpha$ cross-amplify oxidative injury and dysfunction of endothelial cells. J. Lipid Res. $37: 123-135$

Verma, S., M. R. Buchanan, and T. J. Anderson. 2003. Endothelial function testing as a biomarker of vascular disease. Circulation 108:2054-2059.

Viita, H., C. K. Sen, S. Roy, T. Siljamäki, T. Nikkari, and S. Ylä-Herttuala. 1999. High expression of human 15-lipoxygenase induces

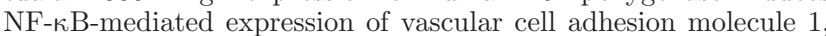
intercellular adhesion molecule 1, and T-cell adhesion on human endothelial cells. Antioxid. Redox Signal. 1:83-96.

Weber, C., W. Erl, A. Pietsch, U. Danesch, and P. C. Weber. 1995. Docosahexaenoic acid selectively attenuates induction of vascular cell adhesion molecule-1 and subsequent monocytic cell adhesion to human endothelial cells stimulated by tumor necrosis factor- $\alpha$. Arterioscler. Thromb. Vasc. Biol. 15:622-628.

Wittwer, J., and M. Hersberger. 2007. The two faces of the 15-lipoxygenase in atherosclerosis. Prostaglandins Leukot. Essent. Fatty Acids 77:67-77.

Yang, J., C. E. Petersen, C.-E. Ha, and N. V. Bhagavan. 2002. Structural insights into human serum albumin-mediated prostaglandin catalysis. Protein Sci. 11:538-545. 